\title{
Decreased regulatory T-cell frequency and interleukin-35 levels in patients with rheumatoid arthritis
}

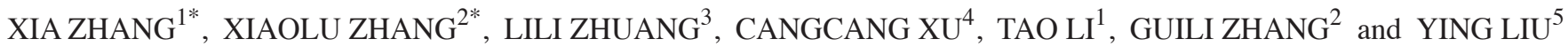 \\ ${ }^{1}$ Department of Immunology, Hunan Normal University School of Medicine, Changsha, Hunan 410013; \\ ${ }^{2}$ Department of Laboratory Medicine, Yuhuangding Hospital of Qingdao University; ${ }^{3}$ Reproductive Medicine Center, \\ Yuhuangding Hospital of Qingdao University, Yantai, Shandong 264000; ${ }^{4}$ Key Laboratory of Study and Discovery of \\ Small Targeted Molecules of Hunan Province, Hunan Normal University School of Medicine, Changsha, Hunan 410013; \\ ${ }^{5}$ Department of Rheumatology, Yuhuangding Hospital of Qingdao University, Yantai, Shandong 264000, P.R. China
}

Received December 31, 2017; Accepted September 18, 2018

DOI: $10.3892 /$ etm.2018.6885

\begin{abstract}
Interleukin-35 (IL-35) is a newly discovered anti-inflammatory cytokine predominantly released by regulatory $\mathrm{T}$ cells (Tregs) and may serve an important role in the pathogenesis of autoimmune diseases. The levels of IL-35 and corresponding Treg frequencies in patients with rheumatoid arthritis (RA) have scarcely been reported. The present study aimed to detect serum IL-35 levels and Treg frequencies in patients with RA, and analyze their association with each other and with indicators of RA. A total of 55 patients with RA, including 37 active-phase (AP) and 18 chronic-phase (CP) cases, as well as 20 healthy controls (HC), were recruited. Clinical parameters, including erythrocyte sedimentation rate (ESR), C-reactive protein (CRP) levels, rheumatoid factor (RF), anti-cyclic citrullinated peptide (CCP) antibody and 28-joint disease activity score (DAS28) were assessed. The Treg frequency in peripheral blood (PB) was determined by flow cytometry. IL-35 mRNA in PB mononuclear cells of the patients with RA was measured by reverse transcription-quantitative polymerase chain reaction analysis, and IL-35 levels in the serum were detected by ELISA. The correlations between IL-35 levels and the abovementioned indexes were analyzed by determining Pearson's correlation coefficient. The results of the present study indicated that the Treg frequency was significantly decreased in patients with RA compared with that in HC. No significant difference in Treg frequency between the AP and CP groups of RA patients was identified. In addition, the serum IL-35 levels and mRNA
\end{abstract}

Correspondence to: Dr Ying Liu, Department of Rheumatology, Yuhuangding Hospital of Qingdao University, 20 Yuhuangding East Road, Yantai, Shandong 264000, P.R. China

E-mail: liuying_emily@163.com

*Contributed equally

Key words: autoimmune disease, rheumatoid arthritis, regulatory $\mathrm{T}$ cells, cytokine, interleukin-35 expression in RA patients were obviously lower than those in the HC. Of note, the serum IL-35 levels were negatively correlated with the ESR and DAS28 of patients with RA, while no correlation with CRP, RF or anti-CCP antibodies was identified. In addition, a significant positive correlation was revealed between serum IL-35 levels and the Treg frequency. These results suggest that IL-35 and Tregs have a protective role regarding the development of RA.

\section{Introduction}

Rheumatoid arthritis (RA) is a chronic autoimmune disease, characterized by pain and stiffness of the joints, inflammatory arthritis and extra-articular involvement. This systematic autoimmune disorder commonly induces the accumulation of immune cells, including T cells, B cells and macrophages, in the inflamed joints, which may lead to synovial hyperplasia, as well as cartilage and bone erosion (1). T cells have an important role in the pathogenesis of RA, which is therefore considered a typical T-cell-mediated disease, which is arbitrated in particular by $\mathrm{CD}^{+}{ }^{+} \mathrm{T}$ helper $(\mathrm{Th})$ cells. Regulatory $\mathrm{T}$ cells (Tregs) are another subtype of T cells, which exert a suppressive effect and are considered to have a protective role against the autoimmune response (2).

Treg cells were initially identified as $\mathrm{CD} 4{ }^{+} \mathrm{CD} 25^{\text {high }} \mathrm{T}$ cells, and the most recent accurately characterized Treg population is $\mathrm{CD} 4{ }^{+} \mathrm{CD} 25^{\text {high }}$ Forkhead box (Fox)P $3^{+}$. Studies have indicated that the majority of the Foxp $3^{+}$Tregs are however within the $\mathrm{CD} 4^{+} \mathrm{CD} 25^{\text {high }} \mathrm{CD} 127^{-}$cell population; the latter population is therefore usually used for determining the Treg cell count and function (3). Since their identification, a number of studies have investigated the number and function of Tregs in RA patients. Tregs have been suggested to have a protective role in mouse models of arthritis $(4,5)$. However, although a number of studies have come to the same conclusion that Tregs were enriched in RA synovial fluid, reports on Treg proportions in the peripheral blood $(\mathrm{PB})$ of patients with RA have provided conflicting results. The majority of studies indicated that the percentage of circulating Tregs in RA was reduced compared with that in healthy individuals, while others have reported increased or similar cell percentages in RA patients compared 
with those in normal controls or patients with osteoarthritis (OA) (6-9).

Although Tregs are thought to exert their suppressive effect via secretion of the inhibitory cytokines interleukin (IL)-10 and transforming growth factor- $\beta$, and cell-cell contact via cytotoxic T-lymphocyte-associated protein 4 and the membrane glycoprotein lymphocyte-activation gene 3 , the exact mechanism of Treg function has remained to be fully elucidated $(10,11)$. IL-35 is a recently discovered cytokine of the IL-12 family, which also includes Epstein-Barr virus induced gene 3 (EBI3) and p35. IL-35 was initially reported to be secreted by Tregs (12) and has recently been revealed to be produced by other cell types, including regulatory B cells and activated B cells $(13,14)$. IL-35 not only has an important role in promoting the suppressive function of Treg cells (12), but also induces the generation of Tregs that produce IL-35 (iTr35 cells); these induced iTr35 cells in turn produce more IL-35 (15). Several studies have assessed the role of IL-35 in autoimmune diseases; in a mouse model, Niedbala et al (16) revealed that recombinant IL-35 effectively attenuated collagen-induced arthritis, and a subsequent study by Kochetkova et al (17) reported similar results. Several clinical studies indicated that serum IL-35 levels were significantly lower in patients with RA; furthermore, treatment with IL-35 suppressed inflammatory cytokine levels and enhanced the regulatory function of Tregs $(18,19)$. However, few studies have analyzed the number and function of Tregs in patients with RA.

In the present study, the IL-35 concentration and Treg frequency in patients with RA was analyzed, and the association between IL-35, Tregs and indicators of RA activity was further explored. This preliminary study provides a basis for understanding the role IL-35 of in RA and may serve as a reference for further investigation to develop novel diagnostic tools or treatments for RA.

\section{Materials and methods}

Patients and clinical data. Peripheral blood was obtained from 37 patients with active-phase RA (PA-AP), 18 patients with chronic-phase RA (RA-CP) and 20 healthy controls (HC). HC subjects were recruited from local staff volunteers. All of the patients with RA fulfilled the American College of Rheumatology criteria for RA (20). The following clinical parameters were acquired from the patients' medical records: Erythrocyte sedimentation rate (ESR), C-reactive protein (CRP) levels, rheumatoid factor (RF) and anti-cyclic citrullinated peptide (CCP) antibody. The 28 -joint disease activity score (DAS28) was used to determine disease activity (21). All patients were free of infectious diseases, cancer, cardiovascular disease and any other inflammatory diseases. The characteristics of the patients with RA and the HC are presented in Table I. The final protocol for the use of patient samples was approved by the local Institutional Review Board of Yantai Yuhuangding Hospital (Yantai, China). All patients and controls voluntarily joined the present study and provided their written informed consent.

Treg detection. For analysis of Tregs, $5 \mu \mathrm{l}$ peridinin chlorophyll cyanine 5.5-conjugated anti-human CD3 (cat no. 340949), $5 \mu 1$ phycoerythrin-conjugated anti-human CD25 (cat no. 341009),
$5 \mu$ fluorescein isothiocyanate-conjugated anti-human CD4 (cat no. 340133) and $5 \mu 1$ Alexa Fluor 647-conjugated anti-human CD127 (cat. no. 558598; all antibodies obtained from BD Biosciences, Franklin Lakes, NJ, USA) were mixed with $100 \mu \mathrm{l}$ fresh EDTA-K2-anti-coagulated whole blood, followed by incubation at room temperature in the dark for $30 \mathrm{~min}$. Equal volumes of corresponding mouse immunoglobulin isotypes: Alexa Fluor 647-conjugated IgG1 isotype (BD Biosciences; cat no. 565571) and phycoerythrin-conjugated IgG1 isotype (BD Biosciences; cat no. 555749) were used as controls. Following incubation, red blood cells were lysed with lysis solution (BD Biosciences; cat. no. 349202) for $10 \mathrm{~min}$ at room temperature and washed with PBS, followed by dilution with $0.5 \mathrm{ml}$ PBS for analysis by flow cytometry. The analysis was performed using a BD FACS Canto II flow cytometer (BD Biosciences). At least 50,000 events were collected for each specimen and the results were analyzed using Diva 7.0 software (BD Biosciences).

RNA extraction and reverse transcription-quantitative polymerase chain reaction $(R T-q P C R)$. PB mononuclear cells (PBMC) were isolated through Ficoll-Hypaque density gradient centrifugation from $\mathrm{PB}$ of patients with RA and the HC. Total mRNA was isolated using TRIzol (Invitrogen; Thermo Fisher Scientific, Inc., Waltham, MA, USA) by the one-step extraction method. RNA concentrations and purity were determined by reading their absorbance at $260 \mathrm{~nm}$. Complementary DNA was prepared using the RevertAid First Strand cDNA Synthesis Kit (Thermo Fisher Scientific, inc.; cat. no. K1622) according to the manufacturer's instructions. Real-time PCR amplification was performed using SYBR ${ }^{\circledR}$ Selected Master mix (Applied Biosystems; Thermo Fisher Scientific). The sequences of specific primer pairs (Invitrogen; Thermo Fisher Scientific Inc.) were as follows: p35 forward, 5'-AGGAATGTTCCCATGCCT TCA-3' and reverse, 5'-CCAATGGTAAACAGGCCTCCA C-3'; EBI3 forward, 5'-TCCCAGAGATCTTCTCACTGA AGTA-3' and reverse, 5'-GCACAGCCCTGAGGATGAA-3'; GAPDH forward, 5'-AACGGATTTGGTCGTATTGGG-3' and reverse, 5'-CCTGGAAGATGGTGATGGGAT-3'. The thermocycling steps were as follows: $95^{\circ} \mathrm{C}$ for $10 \mathrm{~min}$, followed by 39 cycles of $95^{\circ} \mathrm{C}$ for $30 \mathrm{sec}, 60^{\circ} \mathrm{C}$ for $1 \mathrm{~min}$ and $65^{\circ} \mathrm{C}$ for $30 \mathrm{sec}$. Each sample was analyzed in triplicate. The relative mRNA expression was calculated using the $2^{-\Delta \Delta \mathrm{Cq}}$ method (22). All samples were normalized to GAPDH, which was used as a control.

Measurement of serum IL-35 levels by ELISA. Serum IL-35 levels of samples were determined using IL-35 ELISA kits (Cusabio Biotech, Wuhan, China cat no. CSB-E13126 h) according to the manufacturer's protocols. All samples were measured in triplicate and the mean value was calculated for statistical analysis. IL-35 levels were calculated based on a standard curve.

Statistical analysis. Statistical significance was evaluated with data from at least three independent experiments. Statistical comparisons between two groups were performed using an unpaired t-test, while multigroup comparisons were performed by one-way analysis of variance followed by a 
Table I. Clinical parameters of RA patients and HC.

\begin{tabular}{|c|c|c|c|}
\hline Parameter & $\mathrm{HC}(\mathrm{n}=20)$ & $\mathrm{RA}-\mathrm{CP}(\mathrm{n}=18)$ & $\mathrm{RA}-\mathrm{AP}(\mathrm{n}=37)$ \\
\hline \multicolumn{4}{|l|}{ Gender } \\
\hline Male & 10 & 5 & 11 \\
\hline Female & 10 & 13 & 26 \\
\hline \multicolumn{4}{|l|}{ Age (years) } \\
\hline Median range & 43 (26-59) & $53(15-76)$ & $54(18-77)$ \\
\hline CRP (mg/dl) & - & $4.00 \pm 0.43$ & $31.94 \pm 4.96^{\mathrm{a}}$ \\
\hline $\operatorname{ESR}(\mathrm{mm} / \mathrm{h})$ & - & $23.94 \pm 2.64$ & $60.76 \pm 4.09^{a}$ \\
\hline CCP (IU/ml) & - & $65.51 \pm 29.14$ & $114.5 \pm 13.14$ \\
\hline $\mathrm{RF}$ (IU/ml) & - & $318.1 \pm 119.7$ & $461.5 \pm 138.0$ \\
\hline DAS28 & - & $2.20 \pm 0.07$ & $5.67 \pm 0.14^{\mathrm{a}}$ \\
\hline
\end{tabular}

${ }^{\text {aP }}<0.05$ vs. RA-CP. HC, healthy controls; RA-CP, rheumatoid arthritis in chronic phase; RA-AP, RA in active phase; ESR, erythrocyte sedimentation rate; CRP, C-reactive protein; CCP, cyclic citrullinated peptide; RF, rheumatoid factor; DAS28, 28-joint disease activity score.

Table II. Percentage of Th cells and Tregs in RA patients and HC.

\begin{tabular}{lcccc}
\hline Cell type & HC $(\mathrm{n}=20)$ & RA-CP $(\mathrm{n}=18)$ & RA-AP $(\mathrm{n}=37)$ & P-value \\
\hline Th $(\%$ of total T cells $)$ & $53.05 \pm 1.67$ & $58.54 \pm 2.61$ & $60.22 \pm 1.87$ & ${ }^{\mathrm{a}} 0.0159 ;{ }^{\mathrm{b}} 0.0712 ;{ }^{\mathrm{c}} 0.6458$ \\
Treg $(\%$ of total T cells $)$ & $3.55 \pm 0.18$ & $2.69 \pm 0.25$ & $2.90 \pm 0.14$ & ${ }^{\mathrm{a}} 0.0083 ;{ }^{\mathrm{b}} 0.0072 ;{ }^{\mathrm{c}} 0.4701$ \\
Treg/Th & $0.067 \pm 0.003$ & $0.046 \pm 0.004$ & $0.048 \pm 0.002$ & ${ }^{\mathrm{a}}<0.0001 ;{ }^{\mathrm{b}}<0.0001 ;{ }^{\mathrm{c}} 0.5912$
\end{tabular}

${ }^{\mathrm{a}} \mathrm{HC}$ vs. RA-AP; ${ }^{b} \mathrm{HC}$ vs. RA-CP; ${ }^{\mathrm{RA}} \mathrm{C}-\mathrm{CP}$ vs. RA-AP. HC, healthy controls; RA-CP, rheumatoid arthritis in chronic phase; RA-AP, RA in active phase; Th, Thelper; Treg, T-regulatory cell.

Student-Newman-Keuls post-hoc test (Prism 6.0 software; GraphPad Inc., La Jolla, CA, USA). Correlation analysis was performed by determining Pearson's correlation coefficient. Values are expressed as the mean \pm standard error of the mean. $\mathrm{P}<0.05$ was considered to indicate a statistically significant difference.

\section{Results}

Low frequency of $\mathrm{CD}^{+} \mathrm{CD} 25^{+/ \text {high }} \mathrm{CD} 127^{- \text {llow }}$ Tregs in $\mathrm{PB}$ of patients with $R A$. Overall, 55 patients with RA were included in the present study. Their clinical characteristics, including gender, age, CRP, ESR, CCP, RF and DAS28, are presented in Table I. The level of CRP, the ESR and the DAS28 of RA-AP patients were significantly higher than those in RA-CP patients $(\mathrm{P}<0.05)$. However, there was no significant difference in sex, age, RF and CCP levels between the RA-AP and RA-CP groups. Furthermore, $\mathrm{CD}^{+}{ }^{+} \mathrm{T}$ cells and $\mathrm{CD} 4{ }^{+} \mathrm{CD} 25^{\text {high }} \mathrm{CD} 127^{-}$Tregs in patients with $\mathrm{RA}$ and in $\mathrm{HC}$ were analyzed. In Fig. $1 \mathrm{~A}, \mathrm{CD} 3{ }^{+} \mathrm{CD} 4^{+}$cells (gate P3) indicate Th cells and $\mathrm{CD} 25^{\text {high }} \mathrm{CD} 127^{-}$cells (gate P4) indicate Tregs. The percentage of $\mathrm{CD} 25^{\text {high }} \mathrm{CD} 127^{-}$Tregs in patients with $\mathrm{RA}$ (RA-AP or RA-CP) was revealed to be significantly lower than that in $\mathrm{HC}$ (Fig. 1B). However, no significant difference in the percentage of Tregs between the RA-AP and RA-CP groups was identified. The quantified results regarding the T-cell subsets detected are presented in Table II.
IL-35 is decreased in patients with RA. As IL-35 has an important role in the generation and function of Tregs, which themselves produce IL-35, the levels of IL-35 in patients with RA were assessed (Fig. 2). The serum IL-35 levels in the RA-AP patient group $(114.2 \pm 9.097 \mathrm{pg} / \mathrm{ml})$ were significantly lower than those in the RA-CP group $(153.8 \pm 13.83 \mathrm{pg} / \mathrm{ml})$ and the control group $(199.3 \pm 14.45 \mathrm{pg} / \mathrm{ml})$. The serum IL-35 levels in the RA-CP patient group were also significantly lower than those in the control group, which suggests a potential link between IL-35 and disease progression (Fig. 2C). Furthermore, PBMCs were isolated from RA patients and IL-35 mRNA levels were determined with RT-qPCR. Consistent with the above results, the data revealed that mRNA levels of $\mathrm{p} 35$, a subunit of IL-35, were significantly decreased in RA-AP patients compared with those in the RA-CP or control group, and also the p35 levels in the PA-CP group were lower than those in the control group (Fig. 2A). However, no significant difference in EBI3 mRNA expression was detected (Fig. 2B), which may be due to EBI3 also being a component of other cytokines. These results suggested that IL-35 has an important role in the development of RA.

Correlation between IL-35 and disease activity in patients with $R A$. The association between IL-35 and disease activity in RA-AP patients was investigated, and it was revealed that serum IL-35 levels were not significantly correlated with the levels of CRP $(r=-0.1762, P=0.6929$; 

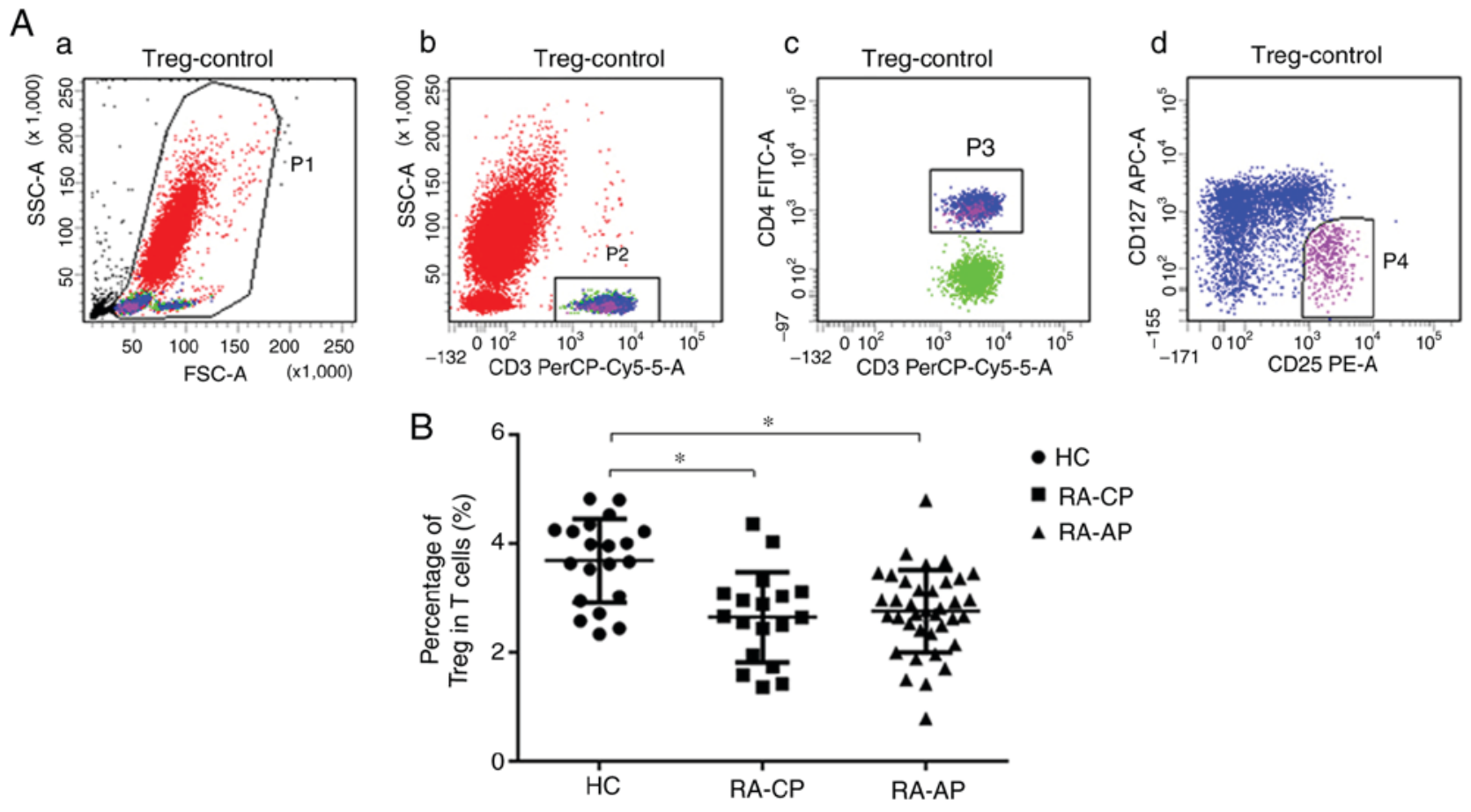

Figure 1. Percentage of $\mathrm{CD} 4^{+} \mathrm{CD} 25^{\text {high }} \mathrm{CD} 127^{-}$Tregs in peripheral blood of RA patients and HC. (A) Representative dot plots of Treg analysis by flow cytometry. (a) Gate P1 (red) contains all of the nucleated cells in the peripheral blood; (b) gate P2 (green) contains the CD3 ${ }^{+} \mathrm{T}$ cells in the P1 gate; (c) gate $\mathrm{P} 3$ (blue) contains $\mathrm{CD}^{+} \mathrm{CD}^{+} \mathrm{T}$ helper cells in the $\mathrm{P} 2$ gate; (d) gate $\mathrm{P} 4$ (purple) includes the $\mathrm{CD}^{+} \mathrm{CD} 4^{+} \mathrm{CD} 25^{\text {high }} \mathrm{CD} 127^{-}$regulatory $\mathrm{T}$ cells in the $\mathrm{P} 3$ gate. (B) Quantified Treg frequency in the PA-AP, RA-CP and HC groups. "P<0.05. RA-AP, rheumatoid arthritis in active phase; RA-CP, RA in chronic phase; HC, healthy controls; Treg, T-regulatory cell; PerCP, peridinin chlorophyll; FSC, forward scatter, SSC, side scatter; Cy, cyanine; FITC, fluorescein isothiocyanate; APC, allophycocyanine.
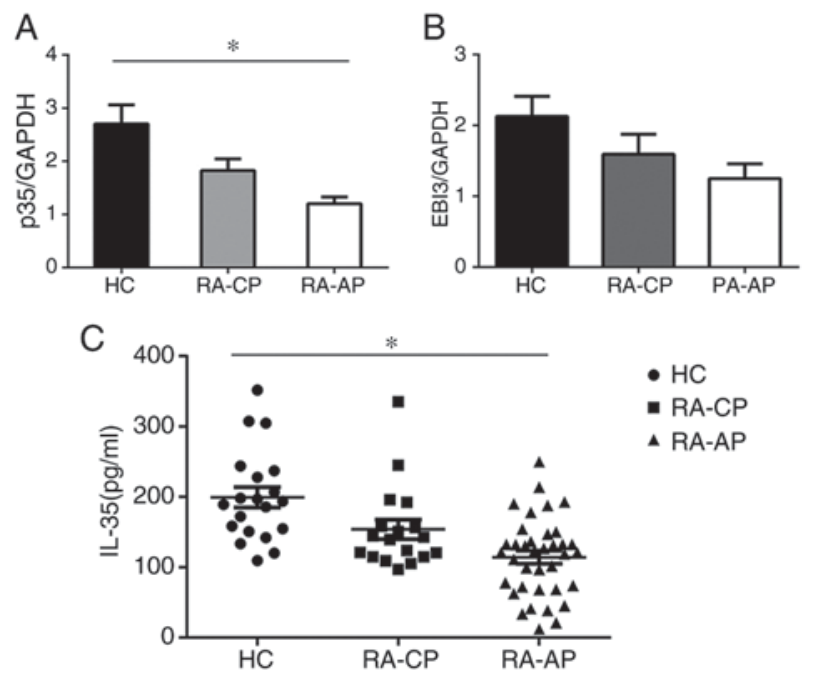

Figure 2. IL-35 levels in patients with RA and in HC. The mRNA expression of (A) p35 and (B) EBI3 IL-35 subunits in the PA-AP, RA-CP and HC groups was analyzed by reverse transcription-quantitative polymerase chain reaction with normalization to GAPDH. (C) Serum IL-35 levels in the PA-AP, RA-CP and HC groups were assessed using a commercial ELISA kit. The solid bars represent the median IL-35 levels. "P<0.05. RA-AP, rheumatoid arthritis in active phase; RA-CP, RA in chronic phase; $\mathrm{HC}$, healthy controls; IL, interleukin; EBI3, Epstein-Barr virus-induced gene 3.

Fig. 3A), RF ( $r=-0.0293, P=0.8693$; Fig. 3C) or anti-CCP antibodies $(r=-0.0822, P=0.6545$; Fig. 3D) in patients with RA. However, serum IL-35 levels were negatively correlated with the ESR ( $r=-0.4247, \mathrm{P}<0.01$; Fig. $3 \mathrm{~B})$ and DAS28 ( $r=-0.4909, \mathrm{P}<0.01$; Fig. $3 \mathrm{E}$ ) in patients with RA.
The DAS28 is an important indicator of disease activity, and therefore, these results further suggested that IL-35 may prevent the progression of RA.

Correlation between IL-35 and percentage of Tregs in patients with $R A$. The correlation between the percentage of Tregs and the DAS28 in RA-AP patients was investigated. The correlation analysis indicated that the percentage of Tregs was negatively correlated with the DAS28 $(r=-0.3615, \mathrm{P}<0.05$; Fig. 4A), which confirmed the role of Tregs in the progression of RA. In addition, the percentages of Tregs were identified to be significantly positively associated with the serum IL-35 concentration $(\mathrm{r}=0.4323, \mathrm{P}<0.01$; Fig. $4 \mathrm{~B})$, which was in accordance with the above. These results suggested that IL-35 may have an immunosuppressive role by enhancing the Treg population in patients with RA.

\section{Discussion}

IL-35 is a newly described anti-inflammatory cytokine involved in various autoimmune diseases, which is produced primarily by Tregs and in turn induces the generation of Tregs $(12,15)$. In the present study, the levels of IL-35 and the percentage of Tregs in RA patients were investigated, and the possible link between IL-35, Tregs and disease activity in RA was analyzed. The results indicated that the IL-35 concentration and the percentage of Tregs in patients with RA was significantly lower than that in HC. In addition, the IL-35 concentration and the percentage of Tregs were negatively correlated with the DAS28, which suggested that IL-35 may 
A

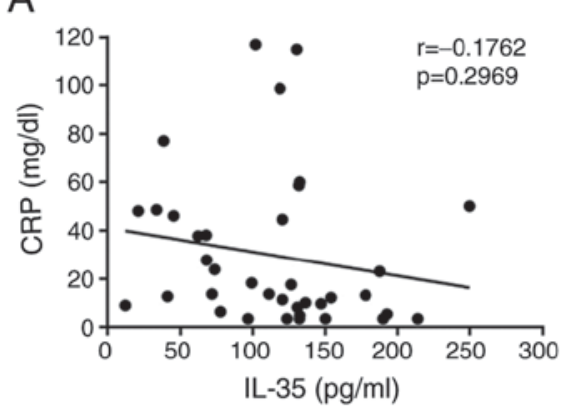

B

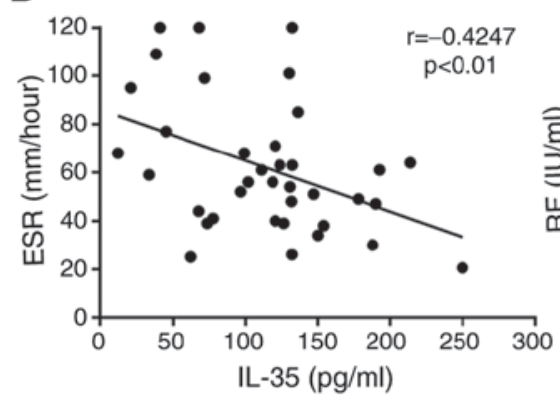

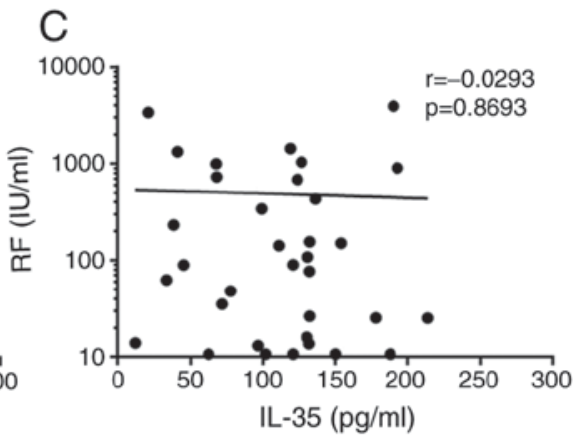
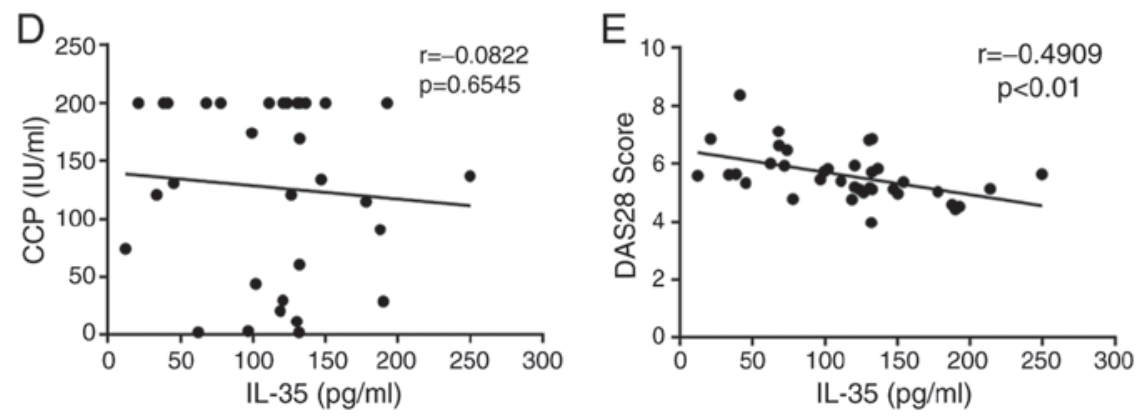

Figure 3. Correlations between IL-35 levels and (A) CRP, (B) ESR, (C) RF, (D) anti-CCP antibody and (E) DAS28 score in patients with rheumatoid arthritis Pearson's correlation coefficient was determined in the correlation analysis. Significant negative correlations were observed between the serum IL-35 concentration and the ESR ( $\mathrm{r}=-0.4247$; P<0.01), as well as the DAS28 ( $\mathrm{r}=-0.4909 ; \mathrm{P}<0.01)$. IL, interleukin; ESR, erythrocyte sedimentation rate; CRP, C-reactive protein; CCP, cyclic citrullinated peptide; RF, rheumatoid factor; DAS28, 28-joint disease activity score.
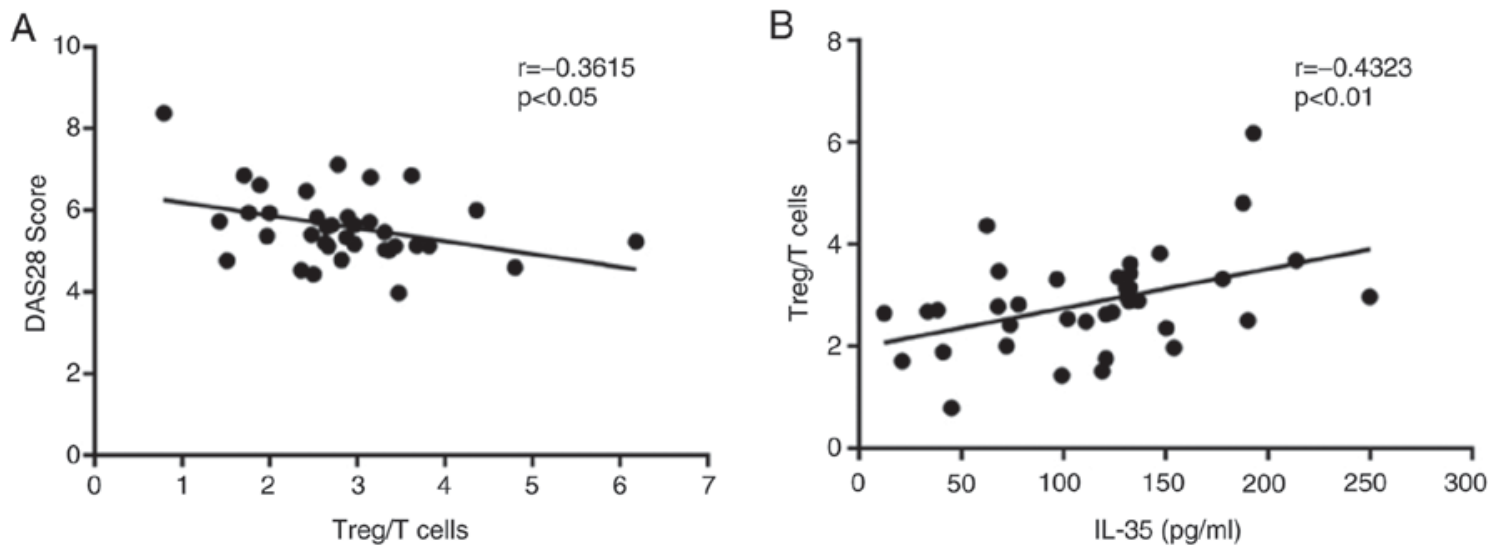

Figure 4. Correlation between IL-35 and the percentage of Tregs in patients with RA. (A) The percentage of Tregs in patients with RA was negatively associated with the DAS28 score $(r=0.3615 ; \mathrm{P}<0.05)$ and $(\mathrm{B})$ significantly positively associated with the serum IL-35 concentration $(\mathrm{r}=0.4323$; $\mathrm{P}<0.01)$. IL, interleukin; Treg, T-regulatory cell; DAS28, 28-joint disease activity score; RA, rheumatoid arthritis.

have a role in the inflammatory processes of RA development.

Several studies have investigated the frequency of Tregs in RA; however, they provided conflicting results, including a decreased, similar or increased Treg percentage compared with that in $\mathrm{HC}$ (7-9). Of note, the establishment of CD127 as an additional surface marker of Tregs has promoted the consistent identification of Tregs as the $\mathrm{CD} 4{ }^{+} \mathrm{CD} 25^{\text {high }} \mathrm{CD} 127$ phenotype (23). To date, only few studies have provided data on $\mathrm{CD} 4{ }^{+} \mathrm{CD} 25^{\text {high }} \mathrm{CD} 127^{-}$Tregs in patients with RA; Kawashiri et al (24) reported that the frequency of Tregs was lower in RA-AP and similar in RA-CP patients compared with that in controls, and Moradi et al (25) indicated that the mean Treg frequency was comparable between RA and OA patients. In the present study, it was revealed that $\mathrm{CD} 4{ }^{+} \mathrm{CD} 25^{\text {high }} \mathrm{CD} 127^{-}$Tregs in RA-AP and RA-CP patients were obviously lower than those in $\mathrm{HC}$. The results indicated that there was no significant difference in the percentage of Tregs between the RA-AP and RA-CP groups, which may be due to the limitation of small sample size; however, these results are consistent with those of previous studies $(24,25)$. In addition, it was also revealed that the Treg frequency was negatively correlated with the DAS28, which suggested a role of Tregs in the development of RA. Administration of Tregs has been indicated to be a promising treatment for autoimmune diseases including RA, and previous studies have reported that induced pluripotent stem cell-derived Tregs suppress arthritis development $(26,27)$. 
IL-35 is primarily involved in the function of Treg effector cells, and therefore, it is important in the study of autoimmune disease (28). Mice deficient of IL-35 produce B cells which cannot recover from $\mathrm{T}$ cell-mediated experimental autoimmune encephalomyelitis (14). However, another study has indicated that IL-35 gene transfer enhanced the severity of collagen-induced arthritis (29). In a clinical study on systemic lupus erythematosus, a decreased IL-35 concentration was detected and a negative correlation with disease severity was observed (30). In multiple sclerosis patients, the serum levels of IL-35 were not different from those in HC (31). In RA, the serum levels of IL-35 were significantly lower than in HC and were negatively correlated with RF, the percentage of neutrophils and articular erosion (18). In the present study, it was also revealed that the serum levels of IL-35 in RA-AP and RA-CP patients was significantly decreased compared with that in HC. It was also indicated that serum IL-35 in the RA-AP patient group was significantly decreased compared with that in the RA-CP group. These results are consistent with those of other studies $(18,19)$. Furthermore, the correlation between the IL-35 concentration and disease activity indicators was analyzed, and the results suggested that serum IL-35 levels were not significantly correlated with CRP, RF or anti-CCP antibodies but negatively correlated with the ESR and DAS28 in patients with RA, which suggests that the levels of IL-35 may reflect RA disease activity. A previous study indicated that recombinant human IL-35 enhanced natural Treg function in vitro and suppressed Treg proliferation and inflammatory cytokines in patients with RA, which suggested that IL-35 is involved in the Treg-mediated suppression of autoimmunity in RA (19). Other studies indicated that IL-35 caused an upregulaion of the expression of Foxp3 and resulted in a significant increase in the proportions of $\mathrm{CD} 4^{+} \mathrm{CD} 25^{+} \mathrm{Foxp} 3^{+}$Tregs in apolipoprotein $\mathrm{E}^{-/-}$mice (32), and administration of IL-35 significantly increased the number of Tregs (33). Consistent with this, the present study revealed that the percentage of Tregs in PB samples was significantly positively correlated with the serum levels of IL-35 in patients with RA. However, the precise regulatory mechanism of IL-35 expression in patients with RA and the molecular pathways involved require to be further elucidated.

In conclusion, the present study revealed decreased serum IL-35 levels and a decreased Treg percentage in patients with RA when compared with those in HC. Further analysis demonstrated that the IL-35 concentration is negatively correlated with the ESR and DAS28, and that the percentage of Tregs is significantly positively correlated with IL-35 levels in patients with RA. This suggested a possible protective role of IL-35 and Tregs regarding the development of RA. Current treatment strategies for RA mainly aim to control inflammation, and in the future, IL-35 and Tregs may provide multiple therapeutic targets.

\section{Acknowledgements}

Not applicable.

\section{Funding}

The current study was supported by The National Natural Science Foundation of China (grant no. 81202069) and the
Natural Scientific Research Foundation of Hunan Province (grant no. 2018JJ3365).

\section{Availability of data and materials}

The datasets used and/or analyzed during the current study are available from the corresponding author on reasonable request.

\section{Authors' contributions}

Xia Zhang and Xiaolu Zhang: Performed the experiments and wrote the paper; Lili Zhuang and Guili Zhang: Collection and assembly of data; Cangcang Xu and Tao Li: Data analysis and manuscript revision. Xia Zhang and Ying Liu: Conception and design, financial support and final approval of manuscript.

\section{Ethical approval and consent to participate}

The final protocol for the use of patient samples was approved by the local Institutional Review Board of Yantai Yuhuangding Hospital (Yantai, China).

\section{Patient consent for publication}

Written informed consent was obtained from all patients prior to enrolment.

\section{Competing interests}

The authors declare that they have no competing interests.

\section{References}

1. McInnes IB and Schett G: The pathogenesis of rheumatoid arthritis. N Engl J Med 365: 2205-2219, 2011.

2. Wing K and Sakaguchi S: Regulatory T cells exert checks and balances on self tolerance and autoimmunity. Nat Immunol 11: 7-13, 2010.

3. Zhang H, Guo H, Lu L, Zahorchak AF, Wiseman RW, Raimondi G, Cooper DK, Ezzelarab MB and Thomson AW: Sequential monitoring and stability of ex vivo expanded autologous and nonautologous regulatory $\mathrm{T}$ cells following infusion in nonhuman primates. Am J Transplant 15: 1253-1266, 2015.

4. Morgan ME, Flierman R, van Duivenvoorde LM, Witteveen HJ, van Ewijk W, van Laar JM, de Vries RR and Toes RE: Effective treatment of collagen induced arthritis by adoptive transfer of CD25+ regulatory T cells. Arthritis Rheum 52: 2212-2221, 2005.

5. Nguyen LT, Jacobs J, Mathis D and Benoist C: Where FoxP3-dependent regulatory T cells impinge on the development of inflammatory arthritis. Arthritis Rheum 56: 509-520, 2007.

6. Alunno A, Manetti M, Caterbi S, Ibba-Manneschi L, Bistoni O, Bartoloni E, Valentini V, Terenzi R and Gerli R: Altered immunoregulation in rheumatoid arthritis: The role of regulatory T cells and proinflammatory Th17 cells and therapeutic implications. Mediators Inflamm 2015: 751793, 2015.

7. Jiao Z, Wang W, Jia R, Li J, You H, Chen L and Wang Y: Accumulation of FoxP3 expressing CD4+CD25+ T cells with distinct chemokine receptors in synovial fluid of patients with active rheumatoid arthritis. Scand J Rheumatol 36: 428-433, 2007.

8. Möttönen M, Heikkinen J, Mustonen L, Isomäki P, Luukkainen R and Lassila O: CD4+ CD25+ T cells with the phenotypic and functional characteristics of regulatory $\mathrm{T}$ cells are enriched in the synovial fluid of patients with rheumatoid arthritis. Clin Exp Immunol 140: 360-367, 2005

9. Han GM, O'Neil-Andersen NJ, Zurier RB and Lawrence DA: $\mathrm{CD} 4+\mathrm{CD} 25$ high $\mathrm{T}$ cell numbers are enriched in the peripheral blood of patients with rheumatoid arthritis. Cell Immunol 253: 92-101, 2008 
10. Sansom DM and Walker LS: The role of CD28 and cytotoxic T-lymphocyte antigen-4 (CTLA-4) in regulatory T-cell biology. Immunol Rev 212: 131-148, 2006.

11. Okamura T, Fujio K, Sumitomo S and Yamamoto K: Roles of LAG3 and EGR2 in regulatory T cells. Ann Rheum Dis 2 (Suppl 71): i96-i100, 2012.

12. Collison LW, Workman CJ, Kuo TT, Boyd K, Wang Y, Vignali KM, Cross R, Sehy D, Blumberg RS and Vignali DA: The inhibitory cytokine IL-35 contributes to regulatory T-cell function. Nature 450: 566-569, 2007.

13. Wang RX, Yu CR, Dambuza IM, Mahdi RM, Dolinska MB, Sergeev YV, Wingfield PT, Kim SH and Egwuagu CE: Interleukin-35 induces regulatory B cells that suppress autoimmune disease. Nat Med 20: 633-641, 2014.

14. Shen P, Roch T, Lampropoulou V, O'Connor RA, Stervbo U, Hilgenberg E, Ries S, Dang VD, Jaimes Y, Daridon C, et al: IL-35-producing B cells are critical regulators of immunity during autoimmune and infectious diseases. Nature 507: 366-370, 2014

15. Collison LW, Chaturvedi V, Henderson AL, Giacomin PR, Guy C, Bankoti J, Finkelstein D, Forbes K, Workman CJ, Brown SA, et al: IL-35-mediated induction of a potent regulatory T cell population. Nat Immunol 11: 1093-1101, 2010.

16. Niedbala W, Wei XQ, Cai B, Hueber AJ, Leung BP, McInnes IB and Liew FY: IL-35 is a novel cytokine with therapeutic effects against collagen-induced arthritis through the expansion of regulatory T cells and suppression of Th17 cells. Eur J Immunol 37: 3021-3029, 2007.

17. Kochetkova I, Golden S, Holderness K, Callis G and Pascual DW: IL-35 stimulation of CD39+ regulatory T cells confers protection against collagen II-induced arthritis via the production of IL-10. J Immunol 184: 7144-7153, 2010.

18. Ning $X$, Jian Z and Wang W: Low serum levels of interleukin 35 in patients with rheumatoid arthritis. Tohoku J Exp Med 237: 77-82, 2015.

19. Nakano S, Morimoto S, Suzuki S, Tsushima H, Yamanaka K, Sekigawa I and Takasaki Y: Immunoregulatory role of IL-35 in $T$ cells of patients with rheumatoid arthritis. Rheumatology (Oxford) 54: 1498-1506, 2015.

20. Arnett FC, Edworthy SM, Bloch DA, McShane DJ, Fries JF, Cooper NS, Healey LA, Kaplan SR, Liang MH and Luthra HS: The american rheumatism association 1987 revised criteria for the classification of rheumatoid arthritis. Arthritis Rheum 31: 315-324, 1988

21. Prevoo ML, van'tHof MA, Kuper HH, van Leewen MA, van de Putte LB and van Riel PL: Modified disease activity scores that include twenty-eight-joint counts. Development and validation in a prospective longitudinal study of patients with rheumatoid arthritis. Arthritis Rheum 38: 44-48, 1995.
22. Livak KJ and Schmittgen TD: Analysis of relative gene expression data using real-time quantitative PCR and the 2(-Delta Delta C(T)) method. Methods 25: 402-408, 2001.

23. Hartigan-O'Connor DJ, Poon C, Sinclair E and McCune JM: Human CD4+ regulatory T cells express lower levels of the IL-7 receptor $\alpha$ chain (CD127), allowing consistent identification and sorting of live cells. J Immunol Methods 319: 41-52, 2007.

24. Kawashiri SY, Kawakami A, Okada A, Koga T, Tamai M, Yamasaki S, Nakamura H, Origuchi T, Ida $\mathrm{H}$ and Eguchi $\mathrm{K}$ : CD4+CD25(high)CD127(low/-) Treg cell frequency from peripheral blood correlates with disease activity in patients with rheumatoid arthritis. J Rheumatol 38: 2517-2521, 2011.

25. Moradi B, Schnatzer P, Hagmann S, Rosshirt N, Gotterbarm T, Kretzer JP, Thomsen M, Lorenz HM, Zeifang F and Tretter T: CD4+CD25+/highCD127low/- regulatory T cells are enriched in rheumatoid arthritis and osteoarthritis joints-analysis of frequency and phenotype in synovial membrane, synovial fluid and peripheral blood. Arthritis Res Ther 16: R97, 2014.

26. Haque R, Lei F, Xiong X, Bian Y, Zhao B, Wu Y and Song J: Programming of regulatory $\mathrm{T}$ cells from pluripotent stem cells and prevention of autoimmunity. J Immunol 189: 1228-1236, 2012.

27. Wright GP, Notley CA, Xue SA, Bendle GM, Holler A, Schumacher TN, Ehrenstein MR and Stauss HJ: Adoptive therapy with redirected primary regulatory $\mathrm{T}$ cells results in antigen-specific suppression of arthritis. Proc Natl Acad Sci USA 106: 19078-19083, 2009.

28. Pope RM and Shahrara S: Possible roles of IL-12-family cytokines in rheumatoid arthritis. Nat Rev Rheumatol 9: 252-256, 2013.

29. Thiolat A, Denys A, Petit M, Biton J, Lemeiter D, Herve R, Lutomski D, Boissier MC and Bessis N: Interleukin-35 gene therapy exacerbates experimental rheumatoid arthritis in mice. Cytokine 69: 87-93, 2014.

30. Ouyang H, Shi YB, Liu ZC, Wang Z, Feng S, Kong SM and Lu Y: Decreased interleukin 35 and CD4+EBI3+ T cells in patients with active systemic lupus erythematosus. Am J Med Sci 348: 156-161, 2014.

31. Jafarzadeh A, Jamali M, Mahdavi R, Ebrahimi HA, Hajghani H, Khosravimashizi A, Nemati M, Najafipour H, Sheikhi A, Mohammadi MM and Daneshvar H: Circulating levels of interleukin-35 in patients with multiple sclerosis: Evaluation of the influences of FOXP3 gene polymorphism and treatment program. J Mol Neurosci 55: 891-897, 2015.

32. Tao L, Zhu J, Chen Y, Wang Q, Pan Y, Yu Q, Zhou B and Zhu H: IL-35 improves Treg-mediated immune suppression in atherosclerotic mice. Exp Ther Med 12: 2469-2476, 2016.

33. Zongyi Y, Funian Z, Hao L, Xin W, Ying C, Jialin Z, Yongfeng L and Baifeng L: Interleukin-35 mitigates the function of murine transplanted islet cells via regulation of Treg/Th17 ratio. PLoS One 12: e0189617, 2017. 